Revista Luna Azul - AS RELAÇÕES OSCILANTES DO HOMEM COM O MUNDO:... Página 1 de 7

\title{
AS RELAÇÕES OSCILANTES DO HOMEM COM O MUNDO: ENTRE FISIOLÓGICAS, MATERIAIS, SAGRADAS E SENSORIAIS
}

\author{
Marlon Javier Méndez Sastoque * \\ Manizales, 2007-10-04 (Rev. 2007-11-03)
}

\section{RESUMO}

No marco do debate em torno às relações natureza-sociedade, o artigo tem como fim reflexionar acerca das relações do homem com seu substrato físico de vida, enfatizando uma questão particular: o caráter oscilante de ditas interações entre fisiológicas, materiais, sagradas e sensoriais. O exposto pretende dar conta dos processos a partir dos quais essa ondulação tem ocorrência; destacando algumas situações específicas: a sujeição original do homem ao meio natural, a atribuição do natural às "leis divinas", a sujeição do natural às "leis do homem" e as intenções de conjunção do separado pelo homem.

\section{PALAVRAS CHAVE}

Natureza e sociedade, modernidade, dessacralização da natureza, razão e paixão.

\section{MAN'S OSCILLATING RELATIONSHIPS WITH THE WORLD: INCLUDING PHYSIOLOGIC, MATERIAL, SACRED AND SENSORIAL RELATIONSHIPS}

\begin{abstract}
Around the discussion on the relationships between nature and society, the objective of this paper is to reflect on man's relationships with his physical substrate of life, emphasizing a particular topic: the oscillating character of his interactions among physiologic, material, sacred and sensorial relationships. The document tries to evidence how those undulations have occurred; highlighting some specific situations: the original subjection of man in a natural way, the attribution of what is natural to "divine laws", the subjection of what is natural to "human laws" and the intentions of conjunction of the separate for man.
\end{abstract}

\section{KEY WORDS}

Nature and society, modernity, desacralization of nature, reason and passion.

* Engenheiro Agrônomo. Mestre em Desenvolvimento e Sociologia Rural. Doutorando em Desenvolvimento, Agricultura e Sociedade, CPDA/ UFRRJ, Brasil. Professor Auxiliar, Departamento de Desenvolvimento Rural, Universidade de Caldas, Colômbia. E-mail: marlon.mendez@ucaldas.edu.co.

Para iniciar, poderíamos dizer que a condição material do homem é ao mesmo tempo principio da sua naturalidade. A vida humana, na sua dependência do corpo, tem lugar 
num entorno material no que essa vida é possível. Sem relacionar-se com o mundo, o homem não pode exercer a sua existência. Como reforça Marx, citado por Bensaïd (1999), o homem é inicialmente um corpo que respira: na origem ele é natureza, um ser natural objetivo. Neste sentido, a relação inicial do homem com o mundo estaria dada através de intercâmbios com seu meio ou substrato físico de vida. Tratar-se-ia de intercâmbios tanto materiais, como fisiológicos, regulados pelas leis da natureza. $\mathrm{Na}$ sua condição biológica e material, o homem encontrar-se-ia sujeito, igual aos outros seres e elementos constitutivos do mundo, às ditas leis naturais.

Partindo do anterior, também poderíamos sugerir que é justamente nessa relação com seu meio físico de vida que, progressivamente, o homem logra-se diferenciar do resto de seres naturais. Como parte dos processos coevolutivos de ajuste, através do pensamento e da sua capacidade transformadora, o homem tem conseguido mudar suas relações com a natureza e os outros homens, tornando-as mais complexas e cheias de rasgos inteiramente humanos. Como afirma Godelier, citado por Diegues (1998), a força mais profunda que movimenta o homem e faz que invente novas formas de sociedade é sua capacidade de mudar suas relações com a natureza. Deste modo poderíamos dizer que as criações do homem não são simplesmente resultados do simples acoplamento a condições naturais, senão da aplicação da sua capacidade transformadora em função de interesses e necessidades "mais humanos", isto é, para além da sua mera condição biológico-material. Assim, de maneira geral, poderíamos afirmar que o ser humano, ademais de unido à natureza, reconhece-se portador de um rasgo qualitativo que o distingue do resto de seres que a conformam: sua capacidade de transformar o mundo (capacidade inovativa), traduzível, por exemplo, em desenvolvimento social e tecnológico: "recriação do mundo a sua imagem e semelhança".

Sem embargo, enquanto esta capacidade estava pouco desenvolvida, poderíamos dizer que a interferência do homem nos processos naturais resultava irrelevante. A natureza, contemplada na sua imponente grandeza e força natural, aparecia como aquele mundo dado para o cumprimento natural do ciclo da vida: nascer, viver, reproduzir e morrer. Desta maneira, a potencia física da natureza apresentava-se ao olhar da pequena e vulnerável figura humana como algo muito superior, e, quiçá por isto, objeto de veneração. Não em vão, muitas das manifestações mais diretas das forças naturais têm sido divinizadas em muitas e diversas culturas. Como anota Eliade (2001), a divinização do céu, a água, a terra, o fogo, a lua, as montanhas, as árvores e os animais constitui uma mostra da sacralidade da natureza. O homem, amparado no reconhecimento da grandeza natural, procurava seu favor mediante o rito e a magia: "quase todo vinha do céu". Não obstante, como aponta novamente Eliade (2001), afastando-se do Deus transcendente, paulatinamente, o homem deixou-se arrastar por suas próprias descobertas. Inicialmente, a experiência religiosa torna-se mais concreta, isto e, mais intimamente misturada da vida, das preocupações cotidianas do homem. Posteriormente, é o homem quem desloca os deuses.

No processo de dessacralização anteriormente apenas esboçado, poderíamos sinalar que o desenvolvimento progressivo da ciência e a tecnologia tem permitido ao homem dominar cada vez mais as forças naturais, assim como configurar âmbitos de vida, mais em função dos seus próprios projetos e interesses, do que unicamente atendendo aos condicionamentos impostos pelo meio natural. O resultado é que o mundo, entendido como entorno de vida do homem, já não refere tanto a uma natureza superior ou às disposições de um criador divino. O mundo posterior alude ao próprio homem, agora em capacidade de manipular e compreender os domínios que regem a própria natureza. É neste afastamento progressivo do divino que poderíamos dizer que a natureza é reduzida a sua simples dimensão mecânico-material. Uma vez coisificada, a natureza é apta para ser explorada e manipulada pelo homem segundo seus próprios interesses. Agora, desde esta nova lógica, a natureza não é mais só objeto de veneração e santidade, senão, sobretudo, objeto de exploração.

Nestes mesmos termos, como assinala Bensaïd (1999), sob a influência "civilizadora" do capital, a natureza fica reduzida a "mero objeto para o homem", isto é, a "uma mera questão de utilidade". Como aponta o mesmo autor, no decorrer da história, sob o influxo capitalista, a formação de um sistema de exploração universal tanto do homem, como do meio natural, reafirmaria o processo de dessacralização da natureza; criando as condições para uma existência humana agora mais que nunca liberada dos seus 
vestígios místicos originais. Ante estas circunstancias, a relação homem-natureza tornar-se-ia completamente material; ficando as relações despojadas de qualquer tipo afetividade ou proximidade extra-sensorial. A maneira de ilustração, como menciona Maldonato (2001), ao referir-se a violência da tecné urbanística, progressivamente, a tentativa de criar espaços genéricos e universais tem comprometido as ligações invisíveis que mantêm unidos espaço e tempo, isto é, o seu poder simbólico. Tratar-seia de aquele poder associado às paixões, às emoções, às raízes de sentido, às saudades e à poesia que são transmitidos aos lugares desde os tempos remotos, e que definem seu caráter sacro.

Baseados no anterior, em termos gerais, poderíamos dizer que, no mundo ocidental, os valores místicos, religiosos e afetivos ligados a certos objetos, lugares, plantas e animais têm sido progressivamente substituídos por valores materiais; adotando um esquema talvez similar ao seguinte: num primeiro período, a exploração da natureza era só de subsistência, isto é, orientada a suprir as necessidades básicas dos homens. Neste mesmo período, deuses, fadas, duendes, mitos e rituais mediavam nessa relação, vigiando, controlando, mais também favorecendo tanto o aproveitamento, como a disponibilidade, das dádivas naturais. Mas, com a morte progressiva desses mediadores e a localização do homem como ser supremo, as relações homemnatureza começaram a mudar. Ante este fato, num momento posterior, agora mediado pela ação do homem, a natureza seria concebida como fonte inanimada de recursos materiais, susceptíveis de ser explorados, não só para suprir as necessidades básicas dos homens, senão para sustentar a acumulação e o crescimento econômico, via geração de excedentes. Neste novo período, os bens da natureza virariam mercadorias e instaurar-se-ia a competição entre os homens; agora produtores, comerciantes e consumidores, capacitados para introduzir na exploração dos recursos naturais as inovações derivadas da ciência e da tecnologia modernas (Smith, 1988, Diegues, 1999).

Em concordância com o anterior, como assinala Leis (1999), uma característica fundamental da modernidade seria a secularização do mundo. Não obstante, como aponta o mesmo autor, dita secularização não deve ser entendida como a eliminação completa da vida espiritual, mas sim como a substituição de um tipo de espiritualidade por outra: a "divindade da natureza" pela "divindade da ordem social humana". Aqui é o homem quem se erige no centro do universo e instaura o reinado da racionalidade. É seu poder divinizado o que o eleva por encima da natureza, e legitima sua exploração em procura do bem-estar social e individual. De igual forma, como expressão da racionalidade humana, a ciência é dotada de um caráter sagrado; outorgado por sua condição universal e por sua pretensão de objetividade suprema.

Sob anterior leitura, a natureza em toda sua extensão não seria mais que um sistema mecânico inanimado, cujo estudo e compreensão demanda ao homem abandonar qualquer olhar emocional; assim como qualquer forma de pensamento não adequado aos parâmetros da racionalidade técnico-científica. Neste sentido, poderíamos dizer que a idéia de natureza inanimada, assimilável a qualquer sistema mecânico sujeito a leis observáveis e comprováveis de funcionamento, serviria à sociedade ocidental para afiançar certa sensação de tranqüilidade e domínio sobre o natural. Com a adoção do olhar científico, tanto a infinidade do poder da natureza, como o mistério que conota sua origem divina, ficariam um pouco apaziguadas, dissipadas e esquecidas; não sendo mais uma preocupação cotidiana ou prioritária. Como menciona Moreira (2002), nas circunstancias descritas, o projeto da ciência consistiria em alcançar a verdade absoluta a partir da pesquisa da natureza e suas leis. Segundo esta visão, as incertezas e angústias que o desconhecido provoca na humanidade seriam atribuídas a um saber ainda incompleto; situação que poderia ser superada pela racionalização do pensamento e o avanço do saber científico.

Contudo, apesar da dominância do processo anotado, não todas as sociedades têm feito o mesmo percurso. Olhadas como sobreviventes de tempos anteriores, imersas no próprio mundo ocidental, hoje ainda persistem "sociedades tradicionais". Mas, em termos das relações homem-natureza, e olhando a partir do hegemon, em que se fundamenta esse caráter distintivo? Segundo Diegues (1998), um aspecto relevante na definição das sociedades tradicionais é a existência de sistemas de manejo dos recursos, marcados pelo respeito aos ciclos naturais; os quais, sem chegar a descartar sua funcionalidade econômica, revelam a existência de um complexo de 
conhecimentos adquiridos e reproduzidos através do tempo, assim como a presencia de mitos e símbolos que guiam as relações com os ecossistemas. Como sinala Candido (1964), citado por Diegues (1998), ao referir-se ao modo de vida caipira: magia, medicina simpática, invocação divina e conhecimentos agrícolas fundem-se num sistema que envolve, na mesma continuidade, o campo, a mata, a semente, o ar, o bicho, a água e o próprio céu.

Como é possível deduzir do anterior, nas circunstancias descritas, o homem membro da sociedade tradicional seria ao mesmo tempo, social, natural e sobrenatural. Não obstante, sua cercania com a natureza e sua evocação sacra da vida fariam dele um ser misterioso ou pelo menos estranho para o homem "civilizado". Como argumenta Moreira (2003), no molde das revoluções científica, burguesa e industrial, as valorizações culturais e econômicas da cidade e a indústria desqualificaram saberes e outras racionalidades distintas da técnico-científica. Culturas como as camponesas e outras também não-hegemônicas passaram a ser vistas como irracionais e incivilizadas; por tanto sujeitas ao domínio e a transformação, assim como a políticas de modernização específica. Seguindo esta leitura, pareceria que uma sociedade, à medida que vai madurando e fazendo-se mais complexa, quisera abandonar paulatinamente tanto as marcas derivadas da origem material e biológica dos seus membros, como seus fundamentos ancestrais míticos e religiosos, para privilegiar a ordem dominada pelo pensamento racional; afastando-se cada vez mais dos modos de pensar "primitivos" e "animistas". Mas, olhando para além do aceitado como certo, na vida cotidiana dos homens comuns, quão efetivo é esse afastamento?

Como menciona Eliade (2001), a experiência de uma natureza radicalmente dessacralizada é uma descoberta recente, acessível apenas a uma minoria das sociedades modernas, sobretudo aos homens de ciência; pelo que, apesar do até agora exposto, é preciso considerar que em muitos homens ainda continua existindo pelo menos uma vaga sensação de natureza sagrada. Para muitos deles, a natureza apresenta ainda um "encanto", um "mistério", onde se podem decifrar os traços dos antigos valores místicos e religiosos. Seguindo este enfoque, poderíamos dizer que o desejo de voltar à natureza abandonando o modo de vida citadino, ou a necessidade de encontrar inspiração no campo ou em outro tipo de lugares ainda à margem da intervenção humana, resgatam dito sentimento residual. De igual forma, os vínculos emocionais das pessoas com certos espaços, objetos ou lugares específicos, bem seja associados à infância ou a importantes momentos das suas vidas; a empatia pelos animais ou plantas; a sensação de unidade mística com o mundo natural experimentado por alguns; a persistência da educação das crianças em ambientes animistas de contos de fadas e animais que falam; assim como o comum avivamento da natureza através de canções, poemas e outras elaborações artísticas poderiam ser também interpretados como continuidades do mundo encantando ou expressões de um processo de re-sacralização do mundo, senão como continuidade de uma sacralidade não totalmente acabada. Mas, esta sensação de encantamento e mistério, é tão só experimentada no plano individual ou subjetivo?

Em termos gerais, poderíamos dizer que hoje é possível observar como as ciências encontram-se mais abertas a concepções distintas às atualmente hegemônicas. Hoje em dia, o chamado à interdisciplinariedade e à transdiciplinariedade é uma questão cada vez mais comum; visão deliberadamente aberta na medida em que supera o domínio das ciências naturais e exatas pelo seu diálogo e reconciliação não somente com as ciências humanas, mas também com as artes e as experiências subjetivas. A maneira de ilustração, tomando a questão ambiental como eixo integrador das sociedades contemporâneas, Leis (1999) sinaliza que a crise ecológica não tem alternativas realistas fora de um ambientalismo sustentado numa ética complexa e multidimensional que recupere o sentido da fraternidade e da espiritualidade da vida social e natural. Desde esta óptica, o resultado de qualquer ação social não pode ser unicamente medido em termos da sua contribuição ao progresso econômico ou tecnológico. Além desta, é necessário considerar suas conseqüências para o progresso moral e a evolução da vida em geral. Neste caso, o chamado a assumir a problemática ambiental desde uma perspectiva multidimensional, e não simplesmente técnicocientífica, constituiria uma mostra do dito.

Em termos da procura de respostas à questão ambiental, leituras como a anterior sugerem que a ciência e a tecnologia não são suficientes para responder por si 
mesmas ao desafio que hoje isto supõe. Uma abordagem efetiva do problema demanda integrar distintas esferas de análise e compreensão, superando a visão propriamente mecânica, sustentada no desenvolvimento tecnológico como única e desejada solução possível. Neste novo contexto, as esferas material, filosófica, científica, tecnológica, social, cultural, ética e espiritual têm que ser consideradas conjuntamente. Ante esta sugestão, elucidar as tensões entre o objetivo e o subjetivo, entre saber científico e saber popular, entre natureza e sociedade, entre biosfera e noosfera, vira uma necessidade urgente; pois, como questiona Prigogine (1997), ante os problemas que envolvem nossa existência, como pode uma pessoa deixar de ver esses problemas simultaneamente como o olho da razão e o olho da paixão?

De igual forma, no plano científico, hoje também é possível acompanhar esse tipo de encontros e relativização de certezas. Como menciona Wilber (1995), para o caso da física, o interesse de cientistas influentes pela metafísica é uma mostra da transformação evidenciada. Cada vez mais, o movimento da nova física demonstra que há um interesse profundo por assuntos como a filosofia perene ou as realidades transcendentes; até só umas décadas, temáticas totalmente alheias ao mundo das chamadas ciências "duras". Igualmente, passando ao mundo das ciências do homem, o espaço para o reencontro também estaria vigente. Nas ciências sociais, a descontinuidade entre indivíduos e sociedade começa a desaparecer. Como sugere Elias (1994), as cercas artificiais que hoje erigimos no pensamento, dividindo os seres humanos em várias áreas de controle (os campos dos sociólogos, dos antropólogos, dos psicólogos e os historiadores, por exemplo) deveriam ser derrubadas. Segundo esta postura, as estruturas da psique, da sociedade e da historia humana são indissociavelmente complementares, pelo que só poderiam ser estudadas em conjunto; formando, ao lado de outras estruturas, o objeto de uma única ciência humana.

Por outro lado, a idéia que opõe o material ao socialmente construído também começa a ser relativizada. A este respeito, como assinala Whitehead (1994), a natureza se apresenta como um complexo passageiro de eventos que só ganha sentido na realidade humana na relação observador-natureza. De acordo com este autor, sempre associada a sua natureza física, cada partícula de evento seria tanto um instante de tempo como um ponto no espaço; sendo na definição das coordenadas espaciais e temporais que o observador formaria parte do evento: é sua visão a que faria o recorte, a que definiria o instante da observação, a que fixaria "onde", "quando" e "através de que lente olhar e intervir". Assumindo uma postura similar, Moreira (2006) argumenta que o objeto material ou físico apreensível pelos humanos não seria nunca a natureza em si nem pura invenção ou imaginação; este seria, sempre, um objeto social e cultural do ser humano localizado na Terra. Tratar-se-ia de objetos distintamente significados, isto é, de objetos que cobram sentido em diferentes tempos e espaços, em diferentes mundos e diferentes realidades; fato que sugeriria a adoção de uma idéia mais equilibrada da relação entre o homem, a sociedade e suas condições materiais, superando as posturas confinadas tanto ao determinismo biológico como ao determinismo social. Em ultima instancia, trata-se de acrescentar o diálogo entre aquele que conhece e o que é conhecido.

Em termos gerais poderíamos dizer que no mundo da racionalidade científica, a idéia de que as leis e as regularidades só têm uma vigência temporal começa a ganhar espaço. Como anota Prigogine (1996) ao referir-se ao labor científico, atualmente, ninguém poderia pretender possuir a resposta final, pelo que a formulação de leis naturais deveria fazer-se mais em termos de possibilidades, do que determinações; fato que, em coincidência com o exposto por Moreira (2002), estaria dando conta da emergência do relativismo científico como fonte de desreificação da ciência e da razão. No sentido outorgado pelo autor, na pós-modernidade de nossos dias, o fundamento da realidade encontrar-se-ia na cultura. A vida passaria a ter sentido apenas em nós mesmos e os diversos fundamentos que apóiam essas realidades estariam sujeitos a dúvida; pelo que, na medida em que coexistem distintas verdades, toda representação seria discutível.

Como é possível apreciar, a idéia de que todo fato está submetido a regularidades e que em principio é totalmente previsível tem dado passo à incerteza e á espontaneidade dos eventos. Sem que isto signifique uma simples volta ao passado, é neste sentido que poderíamos dizer que os "invisíveis" poderes organizadores da natureza estão de novo emergindo através de distintas expressões. Novamente, a 
natureza é olhada na sua grandeza e mistério. Seguindo esta perspectiva, sobre ela, ainda não todo está dito, ainda há espaço para a surpresa e o acaso. Neste sentido, a vigência da ciência e dos conhecimentos atuais torna-se limitada. Trata-se de uma visão relativista que, de certa forma, deslegitimaria as pretensões positivistas dominantes.

Como comenta Prigogine (1996), citando a Richard Tarnas: "a paixão mais profunda do espírito ocidental foi a de reencontrar sua unidade com as raízes de seu ser"; paixão que levou a afirmar o poder da razão, mas que hoje em dia seria capaz de levar a um novo tipo de unidade em nossa visão de mundo. Para o mesmo autor, a imaginação dos possíveis, a especulação sobre o que poderia ter sido, ou poderia ser, é um dos traços fundamentais da inteligência humana; sendo essa "capacidade de imaginar e transformar" a que haveria de permitir, no momento atual, o surgimento da visão holística do mundo; olhar integrador de distintas perspectivas e caminhos. Segundo esta miragem, o atual seria o tempo dos encontros e os diálogos. Tratar-se-ia da conjunção epistemológica entre as ciências naturais e a filosofia, do diálogo aberto entre o conhecimento científico e os outros tipos de saberes existentes, da proximidade de interesses entre cientistas e leigos, e do vinculo estreito entre a ração e a paixão; encontros que em conjunto apontariam à construção de um mundo imaginado talvez mais justo, solidário e sustentável.

Mas, ante a forte resistência à mudança oferecida pela ordem socialmente instaurada, o que implicaria favorecer ditos encontros?

Apoiados na visão de Castoriadis (1999), poderíamos dizer que assumir as mudanças anotadas implicaria, sobretudo, romper o "fechamento" imposto pela força das crenças hegemônicas. Na narrativa aqui descrita, tratar-se-ia de quebrar a dominância da racionalidade técnico-científica, que nega ou desconhece outro tipo de racionalidades; de superar a visão compartimentalizada do mundo, que centra a atenção nas partes, perdendo de vista a unidade do "todo"; de reconsiderar a idéia que assimila natureza a bem de uso, reduzindo sua valoração a termos mercantis, dando lugar a outro tipo de relações; e de repensar a noção da neutralidade da ciência, que esquece a "humanidade" do observador-científico, sempre orientado pelas suas preferências e abstrações; supostos que, em conjunto, estariam configurando parte da rede de significações socialmente instituídas pela cultura ocidental. Nestas circunstancias, seria a onipotência dessa rede a que seria posta em dúvida, isto é, sua capacidade de conter e poder gerar respostas para qualquer questão surgida no seio da sociedade considerada. Em palavras de Castoriadis (1999), tratar-se-ia do ressurgimento da duvida: o cotidiano, esse mundo herdado e agora posto em dúvida, não aceita mais ser saturado pelas respostas socialmente instituídas. Tratar-se-ia da pergunta que questiona a crença, aquela que poderia subverter as significações e os sistemas de doação de sentido estabelecidos. Mas, se a chave da mudança está no ressurgimento da dúvida, em que contexto poderia esta emergir?

Apoiados no exposto por Tomasello (2003), poderíamos dizer que a possibilidade de incorporar mudanças na rede de significações dominante encontrar-se-ia na faculdade humana de acumular aprendizagem cultural. Como assinala o autor, no transcurso do tempo, a tradição cultural humana acumula as modificações feitas por diferentes indivíduos. De geração em geração, as formas de conceber e relacionar-se com o mundo são reproduzidas até que resultem úteis ou funcionais, isto é, até ser substituídas por outras mais ajustadas a outro momento específico da história. Neste processo de acumulação de conhecimento reflexiva, o que para uma geração poderia resultar claro, para as precedentes poderia mostrar lados obscuros, motivando o surgimento de olhares alternativos capazes de dar resposta a novos questionamentos e inquietudes.

Para o caso aqui tratado, o nascimento da dúvida teria a ver com o fim das certezas: conhecimento em forma de hipóteses, várias respostas para uma mesma pergunta, difusão dos planos predeterminados, exposição a circunstancias contingentes, diversidade de opções e possibilidades de escolha, por exemplo. Em palavras de Prigogine (1996), hoje encontrar-nos-íamos situados em médio de duas representações encontradas: a de um mundo determinista e a de um mundo arbitrário apenas submetido ao acaso. Nestas circunstancias, o mundo, sem estar totalmente submetido às casualidades, não estaria mais dominado pelas leis determinísticas da ciência ou do sagrado; fato que poderia ser assumido como o inicio da mudança das regras do jogo. 
Revista Luna Azul - AS RELAÇÕES OSCILANTES DO HOMEM COM O MUNDO:... Página 7 de 7

Desta maneira, como assinala Maturana (2003), assimilando o sistema social a um jogo, se as condições aceitas como legítimas pelos participantes mudam enquanto eles disputam a partida, o jogo poderia mudar e tornar-se talvez outro distinto; estando a mudança, para o caso aqui tratado, associada às relações do homem com o mundo.

Com tudo, chegando ao final da reflexão, seria preciso considerar o seguinte: cada mudança, cada olhar dominante, cada intenção de transformação possui seu próprio caráter particular (Whitehead, 1994). Assim como o racionalismo e a ciência positivista são a expressão da cultura emanada num determinado espaço/tempo, o olhar atual que exalta a concepção holística do mundo só pode ser o resultado de um espaço/tempo próximo a esta fala, fora do qual haveria podido ou poderá resultar simplesmente sem sentido.

\section{BIBLIOGRAFIA CITADA}

- Bensaïd, Daniel. 1999. Marx, o intempestivo. Grandezas e misérias de uma aventura crítica (séculos XIX e XX). Rio de Janeiro: Civilização Brasileira.

- Castoriadis, Cornelius. 1999. Feito e a ser feito. As encruzilhadas do labirinto V. Rio de Janeiro: DP\&A.

- Diegues, Antonio. 1998. O mito moderno da natureza intocada. São Paulo: Hucitec.

- Eliade, Mircea. 2001. O sagrado e o profano. A essência das religiões. São Paulo: Martin Fontes.

- Elias, Norbert. 1994. A sociedade dos indivíduos. Rio de Janeiro: Jorge Zahar Editor.

- Leis, Hector. 1999. A modernidade insustentável. As críticas do ambientalismo à sociedade contemporânea. Florianópolis: Vozes-Editora da UFSC.

- Maldonato, Mauro. 2001. A subversão do ser. Identidade, mundo, tempo, espaço: fenomenologias de uma mutação. São Paulo: Peirópolis.

- Maturana, Humberto. 2003. A ontologia da realidade. Belo Horizonte: Editora UFMG.

- Moreira, Roberto. 2002. Ruralidades e globalizações: ensaiando uma interpretação. CPDA. Ruralidades, No 1 (set).

- Moreira, Roberto. 2003. Cultura, política e o mundo rural na contemporaneidade. Estudos, Sociedade e Agricultura 20: 113-143.

- Moreira, Roberto. 2006. Identidades complexas no conhecimento científico sobre comunidades costeiras. Em: Ruralidades, capacitação e desenvolvimento. Presno, B. e Alimonda, H. (orgs.). Viçosa: Editora UFV.

- Prigogine, llya. 1996. O fim das certezas. Tempo, caos e as leis da natureza. São Paulo: Editora Unesp.

- Prigogine, Ilya. 1997. Ciência, razão e paixão. Parcerias Estratégicas 1(3):124137.

- Smith, Neil. 1988. Desenvolvimento desigual. Natureza, capital e a produção do espaço. Rio de Janeiro: Bertrand Brasil.

- Tomasello, Michael. 2003. Origens culturais da aquisição do conhecimento humano. São Paulo: Martins Fontes.

- Whitehead, Alfred. 1994. O conceito de natureza. São Paulo: Martins Fontes. 